\title{
$\mathrm{SP}$ 排液中の未知成分に関する研究*
}

\author{
上野雄造・北浦貞夫**

\section{Studies on the Unknown Components in Sulfite Waste Liquor}

\author{
Uyeno Yuzo and Kitaura Sadao
}

(No.510. Hookadai Apartment Furukogarasu-machi Fukuoka-shi).

On summarizing the previous results about S. W. L, the total sum of the analytical value of every components is low than $80 \%$ of all the solid, and as to the residual part ca. $20 \%$ nothing has bean known.

Various experiments were conducted on this part of unknown substances, by technique of ion exchange resin, conductometric titration, paper-chromatography and the other methods.

Next facts were surely assumed.

Certain high-and low molecular acids are concerned to this.

And further the high molecular acids show much of strongly combined sulfonic acid groups and little loosely combined ones and none of weak acid groups, whereas low melecular acids show much of loosely combines sulfonic acid groups and little strongly combined ones, and show weak acid groups.

As the results of paper chromatography, especially, it is suggested that this low molecular acids consist of sugar sulfonic, aldonic and other undetermined carbonic acids.

緒

\section{論}

SP 排液 (以下 S.W.L. と略) 中の有機成分の分析 は, リグニン・ズルフォン酸 (L.S.) については各種 有機アミンによる沈潵法, または D.C.H.A. 抽出法 による分離が行なわれ，一方還元糖についてはイオン 交換樹脂や，ペーパークロマトグラフィーの応用に上 って，著しい進歩がなされた。

しかし，これらの方法によって求められた分析值を 通覽与る之，S.W.L. 中の有機成分の緩和は，全固型 分に刘し $75 \sim 85 \%$ であり，残余 $20 \%$ 前後の部分に関 しては，現在まであまり触れられていないようであ る。

これらの部分について, Samuelson ら²,3) は,

S.W.L. からアルドン酸を分離定量しているが，これ 以外の不揮登性酸は, 微量のしゅら酸や無機酸を除い ては，ほとんぞ見出されていないように思われる。著 者ら ${ }^{15)}$ 要大消石灰による S. W. L. 沈澱物の中から， L. S. 及び楉類のほかに, マンノン酸, キシロン酸を 検出している。また糖ズルフォン酸の存在が推測され て抢り，いくつかのモデル実験が行なわれているが，

* 原稿受付 36.11 .29

** 興国人絹バルプKK, 研究部
西硫酸パルプの工業的生産の条件に和ける S.W.L中 には実際には確認された例は見られず，その全ぼうは 決して明るいとはいえない(4),5),67,77,8)。このように， これらの成分は，まだ十分に分離されて扮らず，定量 法も確立されていないが，抢そらく L. S.やホロ七ル ローズなどの複雑な分解生成物の混合体であるうと思 われる。

また，これらの成分は，S.W.L.の工業的利用の問 題を考光合わせる際に，幾多の問題を想起させる。す なわち, 粘結剤として濃縮 S. W. L.を利用した場合, その吸湿性の問題，セメントにS.W.L.を混入した場 合の諸障害，ワニリン製造時の過大なアルカリ消費な ぞこれらの原因との関連が考えられる。また，ホ口 セルローズの蒸解時に和ける分解反応についてなんら かの知見が得られることが予想される。

われわれは，以上の未知成分に着目し，伝導度滴定 ペーパー・クロマトグラフィー，イオン交換樹脂の利 用によって，この未知成分の組成について検討した。

\section{実 験 方 法}

\section{（I）未知成分 ( $\mathbf{X}$ と仮称) の含量}

赤松材, レイヨンパルプ用 S P 蒸解時の排液 (プロ 一直前）を採取し，次のような方法で分析した。 
(1) 分 析試 料

分析誤差を少なくするため，S.W.L.より予め灰分， 遊離西硫酸を除去して抢く。50 cc. S. W. L. 原液をダ イヤイオン S. K 101 層に流下し, 貺灰し, 空気を吹 込み，遊離西硫酸をのぞき，樹脂層は蒸溜水で十分に 洗浄し，全量が $250 \mathrm{cc}$ になるようにし，その一定量 を採取し，分析に供する。(本試料 5 cc は S. W.L. 1 ccに相当する)

(口) $\alpha$-L.S. (仮称)

テトラメチル・ジアミノ・ジフェニルメタン塩酸溶 液 (D.P. M. HCl と略) 飞よって沈湟する L. S.を $\alpha$-L. S. とする。

上述試料 25 cc に D.P. M. HCl 溶液 (D.P.M. 3 $\%, \mathrm{~N} / 3 \mathrm{HCl})$ を，もはや沈激が生じなくなるまで加 之, 常温で一夜放置した後に, 滤過, 水洗, 乾燥（減 圧下 $80^{\circ} \mathrm{C}$ ) して秤量し，その N\%より D.P.M. 量を 算出し，沈筂の科量值より羑引いた値を $\alpha$-L. S. とす る。

(W) B-L. S. (仮称)

D.P.M. HCl では沈筑し得ぬが，グリコール・キ トザン (G. ch) 9) で沈澱する L. S. を $\beta$-L. S. とす る。

上試料 $5 \mathrm{cc}$ K N/100 G. ch 酶酸溶液 $40 \mathrm{cc}$ を加 え，トルイジンブルーを指示薬として，当量点まで， ポリビニイズルフォン酸カリ (P.V.S. K.) を加え, 凝 集する沈澱を分離, 洗浄, 乾燥して科量し, 消費 $\mathrm{P}$. V.S.K.により，L.S. を算出し，その㒹から，前 $\alpha$ L. S. の值を差引き $\beta$-L. S. とする。

$\Leftrightarrow$ 全還元糖

上記試料 25 cc をとり，D.P.M. HCl で $\alpha$-L.S.を 除いた滤液について，ベルトラン法で定量する。

$N$ 全固型分

原 S.W.L.5 cc を採取し, 湯浴上で濃縮し， $105^{\circ} \mathrm{C}$ 乾燥器中で，恒量となるまで乾燥し，科量する。

(b) 灰 分

原 S.W.L. 5cc をるつぼにとり，濃縮した後に焼 却し，濃硫酸を加え，硫酸カルシウムとして科量し， カルシウムイオンとして算出する。

(日) 遊離悪硫酸扣よび硫酸

原 S.W.L. 10 cc そつき，Tappi standard に準じ 定量する。

(D) $\mathrm{X}$ の含量算出

$\mathrm{X}$ の含量性全固型分に対する\%で表し，次のように して算出した。

$$
\begin{aligned}
\mathrm{X} \%=\text { 全固型分 }-[(\alpha \text {-L.S. })+(\beta-\text { L.S. }) \\
+(\text { 全還元糖 })+\mathrm{Ca}^{++} \\
\left.+\quad+\text { 遊崔 } \mathrm{SO}_{2}+\mathrm{SO}_{4}^{--}\right] / \text {全固型分 }
\end{aligned}
$$

（II） 伝導度滴定によるXの組成検討

Xを構成するものは，拈そらく，酸性物質ではない かと思われる。何故ならば，S.W.L.をアニリン・フ オルマリン樹脂100汇流下し，酸性物質を除去した中性 液について，2次元ペーパー・クロマトグラフィーを 行なったところ, 単糖類 (グルコース, マンノース, ガラクトース，キシロース，アラビノース）以外のス ポットはほとんぞ見出せなかったからである。

そこで，XをS.W.L.中の酸性分であると教え，伝 導度滴定，一般分析法を組合わせ，この酸性分の組成 について検討した。

\section{（I ～1） 伝導度滴定}

酸としてのXを伝導度滴定する場合, その試料とし ては, S.W.L 中のX以外の成分をすべて除去すること が最も望ましいが，調整試料の濃度，抢よび分離操作 の点から考慮して, 前述した D.P. $\mathrm{H} \mathrm{H}_{2} \mathrm{SO}_{4}$ 溶液で, $\alpha$-L.S のみを除去した試料について滴定を行ならこと にした。陚料調整には，緩結合正硫酸の脱離の起こら ぬよう次のように，イオン交換樹脂を用い，液がアル カリ性にならぬよう留意した。また伝導度滴定におい て，当量点を明確に読むため（特に弱酸当量点）には， S. W. L. 原液に対し希釈度20を越さぬことが望ましい。 （I-1-1） 試料の調整

S. W. L. 原液約 1 Lをダイヤ・イオン S. K 101(H) 層に流下し, 前端流下液約 $300 \mathrm{cc}$ は槀て, 十分に濃 厚な脱灰排液約 $200 \mathrm{cc}$ を採取し, 空気を通じ遊離亚 硫酸を除く。この液飞 D.P.M. $\mathrm{H}_{2} \mathrm{SO}_{4}$ 溶液(D.P.M. $\left.10 \%, \mathrm{~N} / 3 \mathrm{H}_{2} \mathrm{SO}_{4}\right)$ を, もはや沈晸が生じなくなるま で加え, 一夜放置後汇濾過し, 沈澱を蒸溜水で洗浄し, 洗液は滤液と合する。この液を炭酸バリウムで中和す ると, 硫酸は, 硫酸バリウムとして沈激し，また過剩 の D.P.M. の一部も折出する。これらを滤嵒して除 き, 沈湟は水洗し, 滤液に合する。この液を再びダイ ヤイオン SK 101 層に流下すると, バリウムイオン および D.P.M. はダイヤイオンに四着し，得られる 流下液は， $\alpha$-L. S. を含まぬ酸性液である。（図～1 參照)

\section{これを試料 $\mathrm{A}$ とす。}

\section{（II-1-2） 伝導度滴定法}

試料 Aを 10 倍に希釈し*（試料 B とする）その $10 \mathrm{cc}$ をピペットで取り，メタノール約 3 cc を加え，N/50 かせいソーダ溶液で伝導度滴定を抽こない強酸基, 弱 酸基の当量点を求めた。

*) 希䣋の理由は，後述するアニオン交換樹脂の流下 液の滴定值との比較に便なため。 


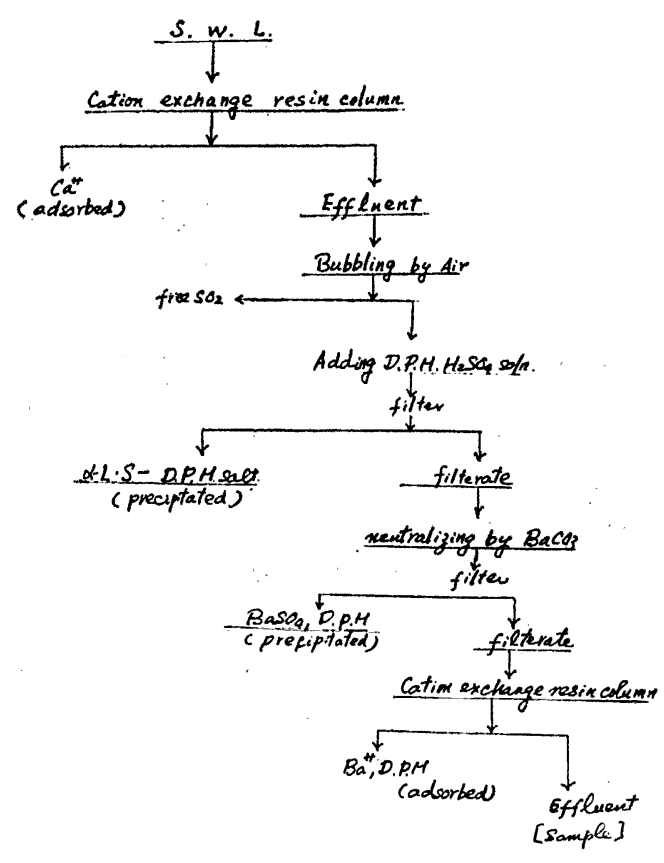

Fig. 1 Preparation of the sample for conductometric titration

（II-1-3） 試料 B の一般分析

試料Bについて，全硫黄（湿式酸化法）， $\beta$-L. S., 全緩結合西硫酸を常法で定量した。な技緩結合覀硫酸 については，特に $\beta$-L. S. と結合するものと，Xに結 合するものとを測定するために， $\beta$-L. S. の定量の際 に生じた L. S. と G. ch の沈被濾過した母液につ いて緩結合亜硫酸を測定し, 全緩結合亜硫酸よりの差 をみて， $\beta$-L. S. と結合するものと考えた。

\section{（III） Xの陰イオン交換樹脂への吸着}

一般隹，S.W.L. を除イオン交換樹脂 Dowex-3， Amberlite IR-4 など）層に流下すると， $\alpha$-L. S.のよ らな高分子の酸は, 樹脂の網目構造内部へ浸透し得ず, わずか樹脂表面に吸着するのみで，そのほとんどが流 下し，樹脂には低分子状の酸の及が吸着されることが
知られている ${ }^{10), 1) 。 ~}$

われわれは，Xを陰イオン交換樹脂 Dowex-3 $(\mathrm{OH}$ 型）層に流下し，その吸着量から，X中に含まれる高 分子和よび低分子酸の比，その他を検索しようとした。 操作はつぎの通りである。

（II-1） Dowex-3 への吸着执よびその流下液の分 析

前述試料 $\mathrm{A}$ （B の 10 倍濃度） $20 \mathrm{cc}$ をとり，弱塩基 性陰イオン交換樹脂 Dowex-3（OH 型）層に流下す る。十分に水洗し，その流下液の全量が $200 \mathrm{cc}$ となる 上うにする。この液の $20 \mathrm{cc}$ を採取し, (この量は, 試 料 Bの $10 \mathrm{cc}$ を樹脂層に流下した場合注相当する) メ タノール $6 \mathrm{cc}$ を加え, N/50 かせいソーダで伝導度 滴定を，拈よび前述一般分析を行ない，各成分の吸着 量を調べた。

（V） 2 次元ペーパー・クロマトクラフィーによる

\section{$\mathrm{X}$ 中の低分子酸の検索}

$\mathrm{X}$ 中，陰イオン交換樹脂に吸着する低分子酸を試料 として，2次元ペーパー・クロマトグラフィーを用い て, 分離展開し, それらのRf. ふん霧試薬に上る発色 などから，含有物質の推定总行なった。

(IV-1) 試料調整

Dowex-3（OH 型）樹脂に，脱灰された S.W.L.を 流下し，よく水洗し，N/2-硫酸で吸着部を溶離する。 溶離漼は，炭酸バリウムで硫酸を除き，バリウム塩溶 液はダイセイオン SK 101 でバリウムイオンを除き， 酸性液を得る。これを $40^{\circ} \mathrm{C}$ 以下で減圧漫縮すると， 赤色を执びたシロップが得られる。このものを試料と する。

(IV-2) 展開溶媒

最も分離効果のよかった溶煤はつぎの通りである。

第 1 溶媒: クロロフォルム: 95\%アルコール：蟻酸

( $1: 1: 0.02)$ (但し容量比)

第 2 溶媒: アルュール:濃アンモ二ア水: 水

$(80: 5: 10)$

(IV-3) 発色試薬

次の発色剂を用いた。

Table 6 Spray reagents

\begin{tabular}{|c|c|c|c|}
\hline Compounds & Spray reagents & Colour & $\begin{array}{c}\text { Litera- } \\
\text { tures }\end{array}$ \\
\cline { 2 - 4 } Acids & $\begin{array}{c}\text { Bromophenol blue } \\
(\mathrm{B} \text {. P. B.) } \\
\mathrm{AgNO}_{3} \text { - } \mathrm{NH}_{4} \mathrm{OH} \\
(0.5 \% \text { soln.) }\end{array}$ & $\begin{array}{c}\text { yellow on a blue } \\
\text { ground }\end{array}$ & $(11)$ \\
$\begin{array}{c}\text { Hydroxy-carboxylic acids } \\
\text { Various derivatives } \\
\text { of carbonhydrates } \\
\text { Compounds containing } \\
\text { sulphur }\end{array}$ & $\begin{array}{c}\mathrm{NaJO}_{4} \text {-spray and then } \\
\mathrm{KMnO}_{4} \text {-spray } \\
\mathrm{NaN}_{3}-\mathrm{J}_{2} \text { sol. }\end{array}$ & $\begin{array}{c}\text { yellow-green on a } \\
\text { red violet ground } \\
\text { white on a brown } \\
\text { ground }\end{array}$ & $(13)$ \\
\hline
\end{tabular}


註） 口紙を風乾し，フォルマリン $2 \%$ 水溶液をる え箖し， $40^{\circ} \mathrm{C}$ で約 10 分乾燥して後に行なう4。
（IV-4） アルドン酸類のRf

モデル物質として，下記のアルドン酸，およびその ラクトンを合成し， Rf を測定しておいた。

Table 5 Rf of aldonic acids and lactones $[\times 10]$

\begin{tabular}{|c|c|c|c|c|c|c|c|c|c|c|}
\hline \multirow{2}{*}{ Solvent } & \multicolumn{2}{|c|}{ Xylonic } & \multicolumn{2}{|c|}{ Arabonic } & \multicolumn{2}{|c|}{ Gluconic } & \multicolumn{2}{|c|}{ Galactonic } & \multicolumn{2}{|c|}{ Mannonic } \\
\hline & $\begin{array}{l}\text { Lactone } \\
\text { (L) }\end{array}$ & $\begin{array}{l}\text { Acid } \\
\text { (A) }\end{array}$ & $\mathrm{L}$ & A & L & $\mathbf{A}$ & $\mathbf{L}$ & A & L & A \\
\hline The 1. st. & 5.0 & 1.8 & 4.8 & 1.2 & 3.4 & 0.8 & 2.8 & 0.5 & 1.7 & 0.2 \\
\hline The 2. nd & 1.7 & 1.7 & 1.9 & 2.3 & 1.6 & 1.6 & 1.4 & 1.4 & 2.9 & 2.2 \\
\hline
\end{tabular}

(IV-5) 展開濾紙

東洋濾紙 No. $51 \quad 40 \mathrm{~cm} \times 40 \mathrm{~cm}$

\section{実験結果および考察}

I'） Xの含量は, S.W.L.の分析值より次のように なった。

Table 1 Analysis of S. W.L.

\begin{tabular}{|c|c|}
\hline Components & $\begin{array}{c}\text { Content } \\
\text { g/S. W.L.l }\end{array}$ \\
\hline Total solid & 213.5 \\
$\alpha$-L. S. & 73.6 \\
$\beta$-L. S. & 18.0 \\
Total reducing sugars & 61.2 \\
ash (as Ca ${ }^{++}$) & 7.8 \\
free $\mathrm{SO}_{2}$ & 0.2 \\
$\mathrm{SO}_{4}^{--}$ & 3.4 \\
\hline
\end{tabular}

$X=49.3 \mathrm{~g} / \mathrm{S} . \mathrm{W} . \mathrm{L} . l$

$X \%=23.2 \% /$ Total solid

このように， G. ch を用いて L. S. を沈澱させた

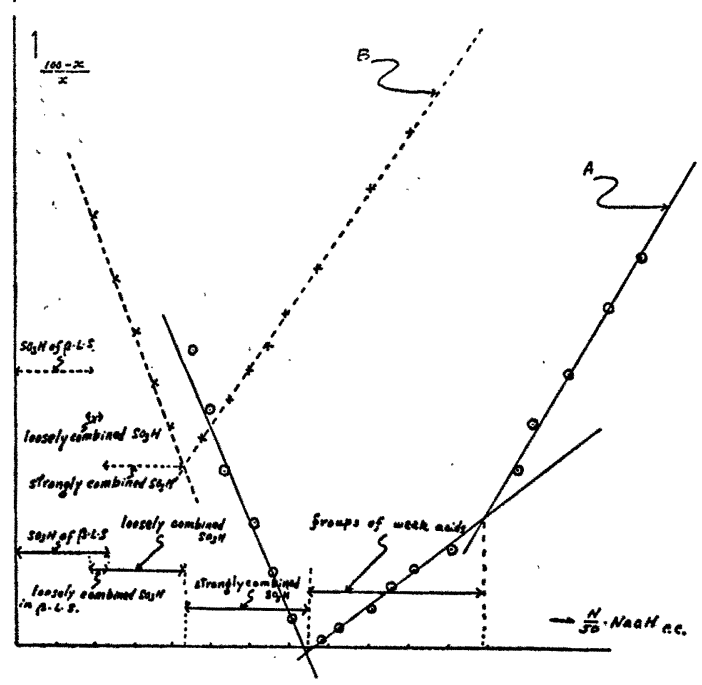

Fig. 2 The conductometric titration curve of $A$ and $\mathrm{B}$ by $\mathrm{N} / 50-\mathrm{NaOH}$

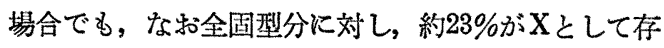
在する。

$\left.\mathbb{I}^{\prime}\right)$ 伝導度滴定および一般分析の結果は，次のよ らになった。滴定曲線は図-2-Aに示す。

Table 2 Analysis of " $X$ " by means of conductometric titration and general methods

\begin{tabular}{|c|c|c|c|}
\hline \multicolumn{2}{|c|}{ Group } & \multicolumn{2}{|c|}{ eq. $\times 10^{-4} /$ sample $^{\text {eq. } \times 10^{-4} /}$} \\
\hline (a) & $\begin{array}{l}\text { Total strong acid } \\
\text { groups }\end{array}$ & 1.48 & 2.30 \\
\hline (b) & Total sulphur & & $\begin{array}{c}\mathrm{BaSO}_{4} 53.4 \\
\mathrm{mg} / \mathrm{cc} \\
2.31\end{array}$ \\
\hline (c) & $\begin{array}{l}\text { Total weak acid } \\
\text { groups }\end{array}$ & 0.91 & 1.46 \\
\hline (d) & $\beta$-L. S. & 0.42 & 0.65 \\
\hline (e) & $\begin{array}{l}\text { Total loosely } \\
\text { combined } \mathrm{SO}_{3} \mathrm{H}\end{array}$ & 0.50 & 0.78 \\
\hline (f) & $\begin{array}{l}\text { Loosely combined } \\
\mathrm{SO}_{3} \mathrm{H} \text { in } \beta-\mathrm{L} . \mathrm{S} \text {. }\end{array}$ & 0.08 & 0.13 \\
\hline & $\begin{array}{l}\text { Strongly combined } \\
\mathrm{SO}_{3} \mathrm{H} \text { in } ~ \\
X\end{array}$ & 0.64 & 1.00 \\
\hline
\end{tabular}

* $(\mathrm{g})=(\mathrm{a})-(\mathrm{d})-(\mathrm{e})+(\mathrm{f})$

** Dilution of $\mathrm{B}$ was determined by concentractions of $\beta$-L. S. and total strong acid grours in B and S. W. L.

これらの結果から次のことが推定される。

(1) 強酸基当量は, 全硫黄定量值とほぼ一致し, ズ ルフォン基であろらと思われる。

（2）ズルフォン基は，アルカリによって脱離する緩 結合の部分と,アルカリ処理によっても脱離しない強 結合の部分が存在する。

（3）緩結合のズルフォン基は，その大部分はX部分 と結合し, $\beta$-L. S. と結合するものは, 全緩結合ズル フォン基に対し約 $20 \%$ である。

'面') Dowex-3 (OH 型) への吸着の結果は次の通り である。

流下液の伝導度滴定曲線は図-2-Bに示す。 
Table 3 Adsorption of " $X$ " by Dowex-3

\begin{tabular}{|c|c|c|c|c|c|}
\hline \multicolumn{2}{|c|}{$\begin{array}{l}\text { Sample } \\
\text { Group }\end{array}$} & $\begin{array}{c}\text { Sample B } \\
\text { (before adsorption) } \\
\left(\text { eq. } \times 10^{-4}\right)\end{array}$ & $\begin{array}{c}\text { Effluent } \\
\begin{array}{c}\text { (after adsorption) } \\
\left(\text { eq. } \times 10^{-4}\right)\end{array}\end{array}$ & $\begin{array}{l}\text { Aisorbed eq. } \\
\text { hy Dower-s } \\
\left(\text { eq. } \times 10^{-4}\right)\end{array}$ & $\begin{array}{l}\text { rate of } \\
\text { ac'sorption } \\
(\%)\end{array}$ \\
\hline \multicolumn{2}{|r|}{$\beta$-L. S. } & 0.42 & 0.40 & 0.02 & 9.5 \\
\hline \multirow{2}{*}{$\mathrm{SO}_{3} \mathrm{H}$} & $\begin{array}{c}\text { Strongly } \\
\text { combined } \mathrm{SO}_{3} \mathrm{HI}\end{array}$ & 0.64 & 0.42 & 0.22 & 34.3 \\
\hline & $\begin{array}{c}\text { Loosely } \\
\text { combined } \mathrm{SO}_{3} \mathrm{H}\end{array}$ & 0.50 & 0.08 & 0.42 & 84.2 \\
\hline \multicolumn{2}{|c|}{ Weak acid group } & 0.91 & 0 & 0 & 100.0 \\
\hline
\end{tabular}

以上の結果から，次のことが推定される。

（1）X中のズルフォン基中，緩結合はその $84.2 \%$ が イオン交換樹脂に吸着し，これらは，糖ズルフォン酸 など低分子状物質と結合するのではないかと思われ る。

（2） X中の強結合ズルフォン基は, 約34\%しか吸着 せず，約66\%は非吸着として流下する。このことは， $\mathrm{X}$ 中のズルフォン酸のうち，イオン交換廚脂に吸着し
得高分子状と思われる酸が相当量含まれると考兄ら れる。

（3）陰イオン交換樹脂に吸着しない高分子部分之想 像されるものの滴定曲線（図-2-B）は明確なV字型 を示し，弱酸基をもたない。このことは，図-2-Aに おける弱酸部がXのみによることを示している。

以上の表-2，3を総合し，Xの構成（当量数 $\times 10^{-4}$ / S.W.L.cc）を要約与ると次の通りである。

Table 4 Composition of " $X$ " [eq. $\left.\times 10^{-4}\right]$

\begin{tabular}{|c|c|c|c|c|}
\hline \multicolumn{1}{|c|}{ Group } & \multicolumn{2}{|c|}{$-\mathrm{SO}_{3} \mathrm{H}$} & Total & Weak acid groups \\
\hline acids & Strongly combined & Loosely combined & & 1.46 \\
\hline Low. Mol. acids & 0.34 & 0.65 & 0.93 & 0 \\
High Mol. acids & 0.66 & 0.13 & 0.77 & 1.46 \\
\hline Total & 1.00 & 0.78 & 1.78 & \\
\hline
\end{tabular}

上表から推定されることは，Xのうち，糖ズルフォ ン酸なと低分子物は，強結合㧍よび䌊結合ズルフォン 基を 3.4 刘 5.4 の比て結合し, 緩結合ズルフォン基を 極めて多く有するものと思われる。

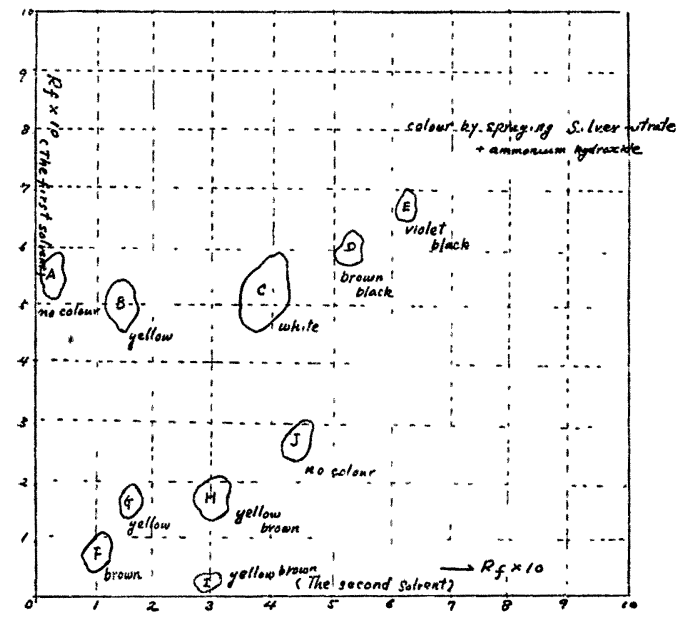

Fig. 3 Chromatogram of low mol. acid in $X$
これに対して，高分子快のものは，瑷結合ズルフォ

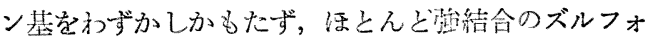

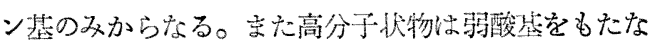
い。

WI) クロマトグラムの倹討

(1) B.P. B. で発色する10コのスポットをA， B … … Jと寺る。

(2) $\mathrm{NaJO}_{4} \cdot \mathrm{KMnO}_{4}$ によってA, B, C, D, E, の5コのスポットが発色する。これ以外のものは， $\mathrm{A}$ ～E汇くらべ，スポットの広さも小さく, 発色も十分 明らかでなかった。

$\mathrm{A} \sim \mathrm{E}$ は糖頪縁化合物と思わ机る。

(3) $\mathrm{NaN}_{3}-\mathrm{J}_{2}$ によって，C，D，E，は茶地に白く 抜恀，含硫化合物之思和机る。

4) 2)3)の結果から， C， D， E，は䌅ズルフォン 酸之想定さ机る。

5）アンモ三ア性硝酸銀によって図示したような特 微める数喠の発色を示す。

6）アルドン酸と考えられるものは， E, G, H, J, で 
あるが，それらが正確に何であるかは明らかでない。 $\mathrm{B}, \mathrm{G}$, はペントン酸のラクトン及びその酸，H，J. は マンノン酸ラクトン就よびその酸と推定される。

7） A, F, J, については，全く不明であるが，アル ドン酸以外のカルボン酸ではないかと思われる。

\section{総括}

以上のべたように, SP 排液中には, 従来, 定量に かからなかった未知成分が，全固型分に対して約 $25 \%$ 存在する。これらの部分についてイオン交換樹脂, 一 般分析，ペーパー・クロマトグラフィーを用いて検討 したところ，この部分（X) には, 高分子状の酸, 打 よび低分子状の酸と思われるものが存在する。

高分子状酸の酸基は，ズルフォン基のみから成り， 弱酸基を持たない。そのズルフォン基はほとんど強結 合であって緩結合は，わずかである。

低分子状酸の酸基は，ズルフォン基および弱酸基 （カルボキシル基と思われる）から成り，そのズルフ オン基は, 高分子酸とは逆に, 強結合より緩結合のも のを多く有している。

またペーパー・クロマトグラムは，低分子酸が，糖 ズルフォン酸と思われるもの, アルドン酸およびその ラクトン，それに未知のカルボン酸と思われるもの，
総計10種の酸の混合物であることを示している。 上述した高分子酸，および低分子酸それぞれの単離 抢よびそれらの確認は現在研究中である。

文献

1) Samuelson, O. Svensk Pap. 59, 388 (1957)

2) " ibid 60, 1043 (1958)

3) $"$ ibid 61, 758 (1960)

4) Yllner, S. Acta. Chem. Scand. 10, 1251 (19 56)

5) 松井 工 化 53, 411 (1949)

6) Heiwinkel, H. Svensk Pap. 47, 265 (1945)

7) Richard H. Tappi 42, 654 (1959)

8) Adler E. Svensk Pap. 49, 339 (1946)

9）千手紙八技協誌 7, 166 (1953)

10）河合, 北浦 九大生産研報告第 4 号 1頁 (1951)

11) Johes, A. R. Dowling, E. J. and Skraba W. J. Anal. Chem. 25, 394 (1953)

12) Hough. L. Nature 165, 400 (1950)

13) Pascu E. Mora. T. P. Kent. P. W. Science 110, 446 (1949)

14) Feigl Spot Test p. 93 G. Kainz and A. Resch Mikrochemie ver. Mikrochim. Acta. 39, $72(1952)$ 15）上野，北浦，滥分技協誌 12,523(1958)

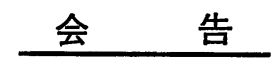

紙パ技術協会

\section{第7回リグニン化学討論会御案内}

記

一, 第 7 回リグニン化学討論会 (日本化学会, 繊維学会, 紙パ技術協会, 日本木材学会, 高分子学 会共催)

一, 日時昭和 37 年 10 月 4 日(木) 5 日(金) 両日

一, 場 所 札棍市北大構内クラーク会館

一, 討 論 主 題 リグニン化学 (単離, 性状, 反応) リグニンの利用, パルプ廃液

一, 研究発表申込 7 月末日までに下記宛御送り下さい。

一, 講 演 要 旨 1000 2000 字程度の要旨を8月末日までに下記宛御送り下さい。

一, 連 絡 場 所 札幌市北九西九 北大畺学部 半沢道郎 (世話役代表)

な特講演時間は 1 題 20 分, 討論時間 10 分を基準と致し度く存じます。又懇親会を 4 日午後 6 時 札幌市内に括いて会費500円で開催の予定です。宿舎旅館予約御希望の方はA (500 円程度) B (1000 円程度) C (1500 円程度) にて御世話致し度く存じますから御希望を御申込欢頂き度く存じ ます。

御発表になられない参加者孔御申込み下さい。 